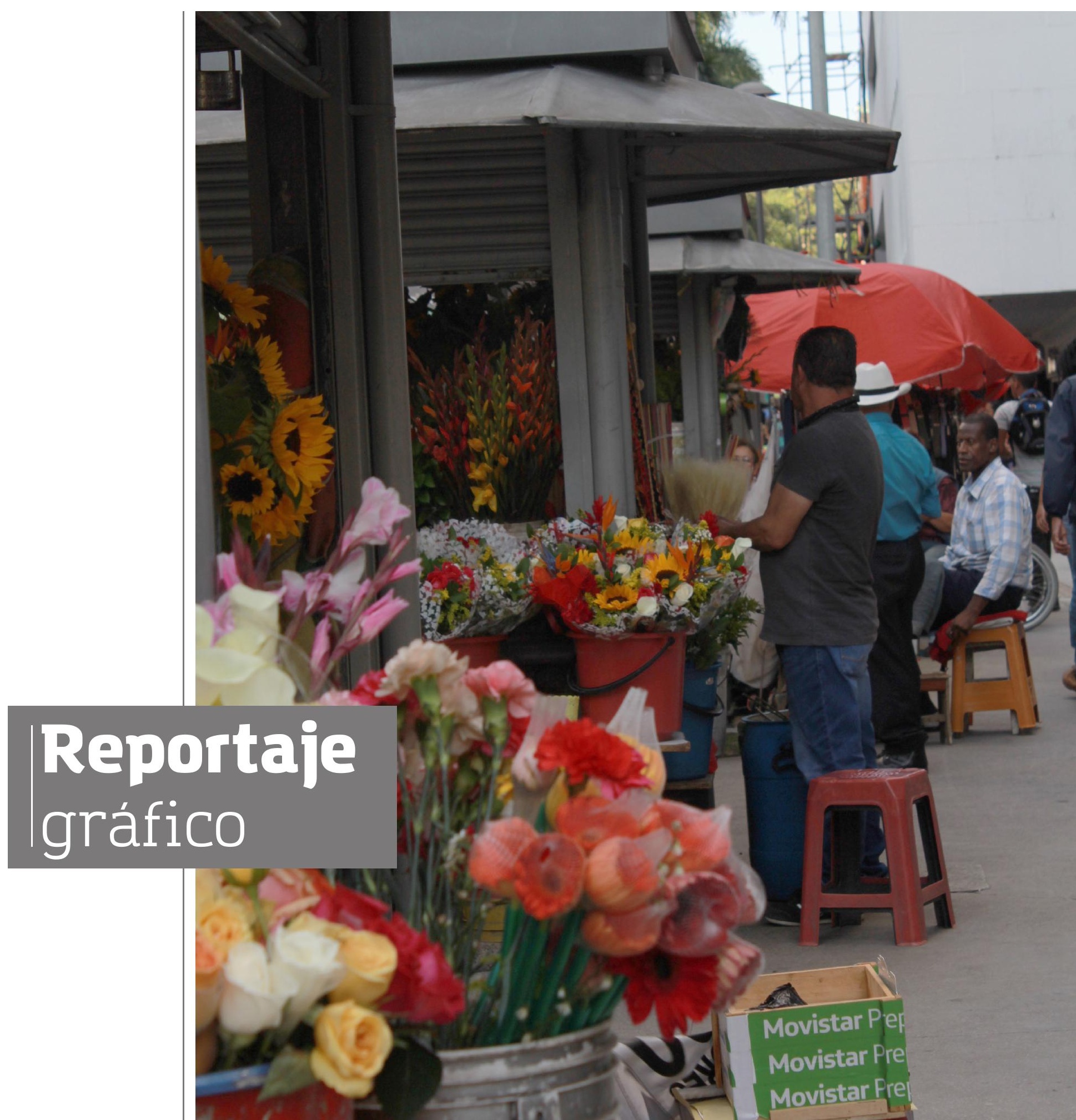




\section{Centro común}

DOI: http://dx.doi.org/10.18566/comunica.n40.a08

Recibido: 28/03/2019 -Aceptado: 29/05/2019

Llegué a una de las cuatro esquinas que hay entre la Oriental y La Playa. Cambió el semáforo. El gentío comenzó a cruzar rápidamente. 50 segundos, me detuve en la calzada en medio de las dos vías de la avenida. Miré sobre el lente y disparé, una, dos, tres... él miró fijamente justo en el cuarto disparo. Miré hacia la Cámara de Comercio y vi el semáforo, 48 segundos, volví a disparar, una, dos, tres, cuatro, esta vez a la quinta ella miró fijamente a la cámara entre el tumulto que iba mientras ella venía. Di unos pasos más y estaba en medio de la calle que va hacia el norte. 14 segundos. Sobre la línea divisora de La Playa estaban estacionadas tres carretas de frutas. Disparé una, dos, tres, miré la pantalla y volví a disparar, 9 segundos, cuatro, cinco y seis disparos más, seguí cruzando hasta llegar al otro lado y cambió el semáforo. Los carros comenzaron a transitar.

Recorriendo las calles, aceras y esquinas del centro de Medellín durante varios meses, surgió en mí la inquietud de conocer y describir las formas de habitarlo. Desde quinto semestre de mi carrera, Comunicación Social Periodismo, me llamó la atención conocer la historia del centro de Medellín, entender sus dinámicas y ritmos caóticos, y contar por medio de las palabras lo que observo al caminar sus calles cotidianamente.

De allí nació mi trabajo de grado Centro Común: lugar habitado, lugar habitable y lugar de encuentro. Una investigación que tuvo como fin describir las formas de habitar el centro de Medellín por parte de distintos actores que viven sus dinámicas sociales, artísticas y culturales. El centro de Medellín, como corazón de la ciudad, es el lugar donde se concentran las actividades y dinámicas propias de la urbe, como el comercio, la industria, la administración pública o la oferta cultural, y esto hace que sea un lugar de encuentro común y socialización.

Tras varios meses de investigación, de entrevistas y observación, obtuve tres historias escritas a modo de crónicas: "Si no habito la ciudad, sigo siendo un forastero", Marisol Zuluaga. "He aprendido a entender al centro desde su interior", Esteban Londoño. Y Calles y encuentros. Historias de residentes, habitantes y lugares emblemáticos del Centro de Medellín.

Además, pude registrar fotográficamente algunos encuentros, usos del espacio público, ritmo y dinámicas del centro, que me dieron otra visión

\section{Laura Valentina} Cardona Correa

Estudiante de noveno semestre de Comunicación Social - Periodismo Universidad Pontificia Bolivariana laura.cardonac@upb.edu.co 
sobre las formas de habitar el centro de Medellín, entendiendo que, entre sus calles y aceras, sus rincones y esquinas, sus locales y tiendas, sus chuzos y fachadas, se encuentran cientos de historias por contar y vivir. Y esta es una cuestión que me apasiona enormemente.

Andar, sentarse, mirar; volver a andar. Buscar, rebuscar y comprar objetos de mil pesos. Correr antes de que cambie el semáforo, caminar de prisa, seguir mirando. Zigzaguear por las carretas y evadir a los que entregan papelitos de casa de masajes o chamanes. Bajar a la Gorda y ver los corrillos reunidos en el Parque Berrío, unos conversan, otros juegan, otras escuchan cantar a la cuadrilla de guitarras, y algún otro está organizando algún cuadre con alguna tintera. Cae la tarde, desemboca en el centro cientos de personas más que salen de trabajar. Panaderías en cada esquina, chucherías en las aceras, buses estacionados que van y vienen, paraderos llenos. Rojo después verde y cruzar una vez más.

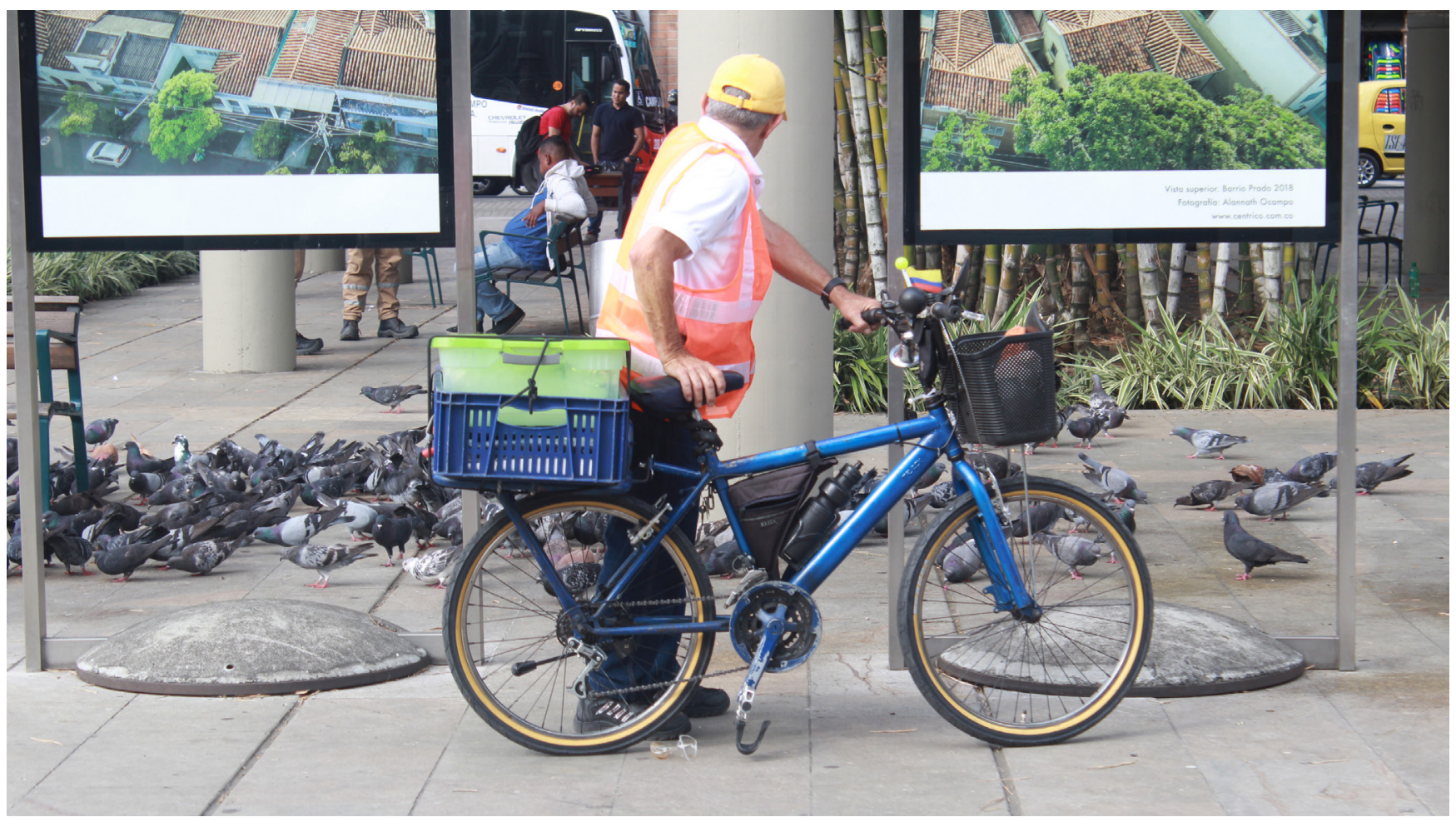



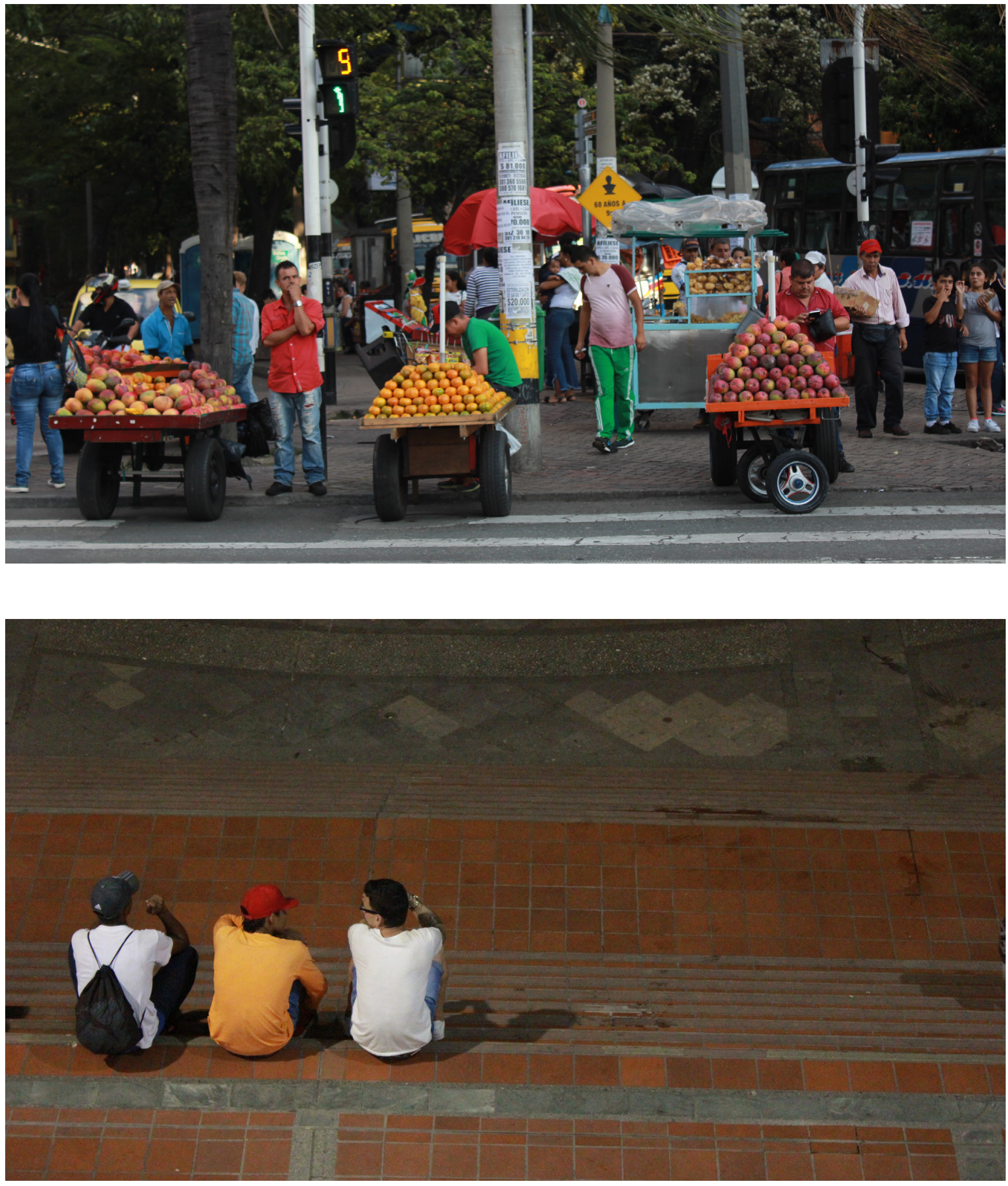

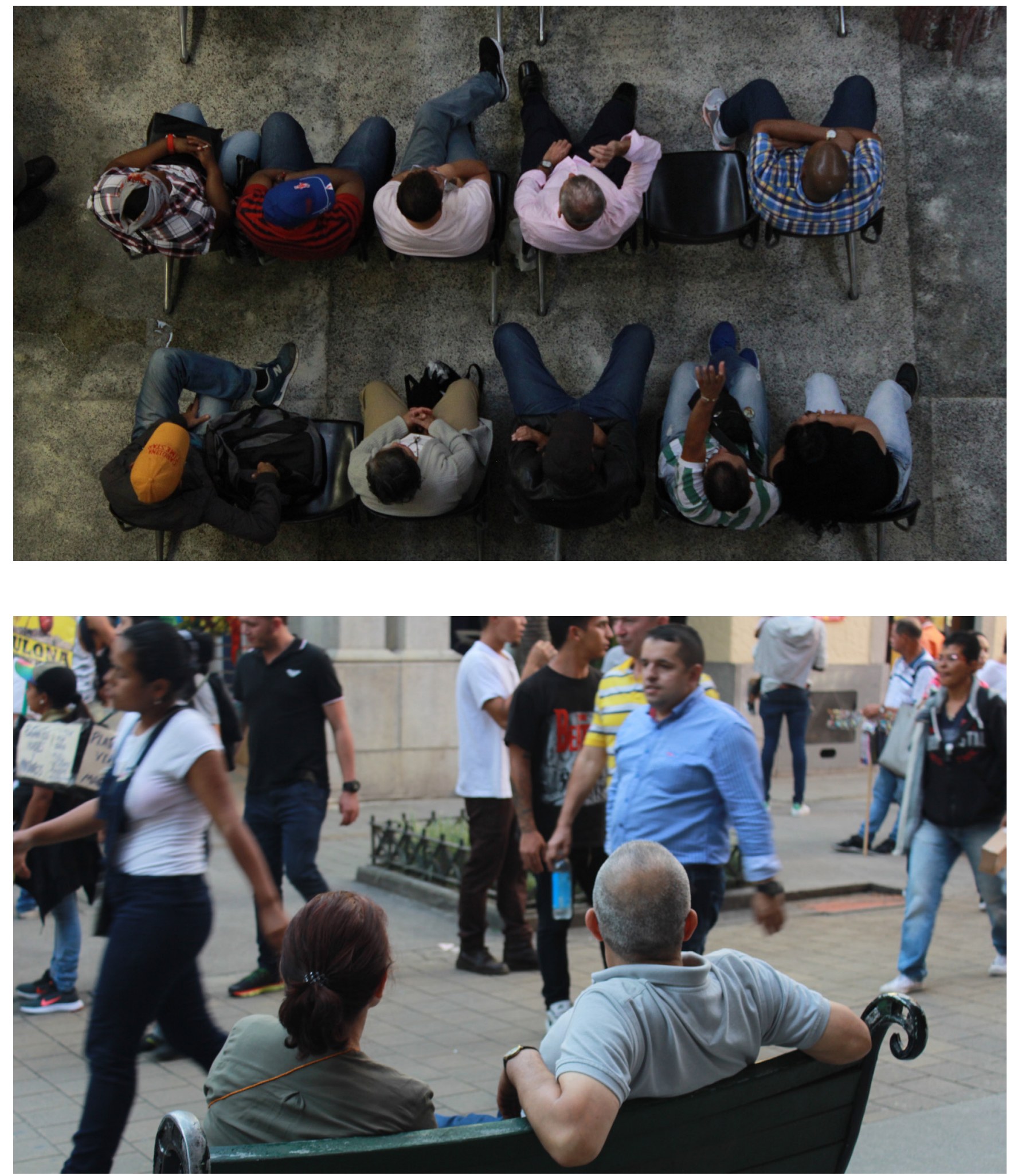

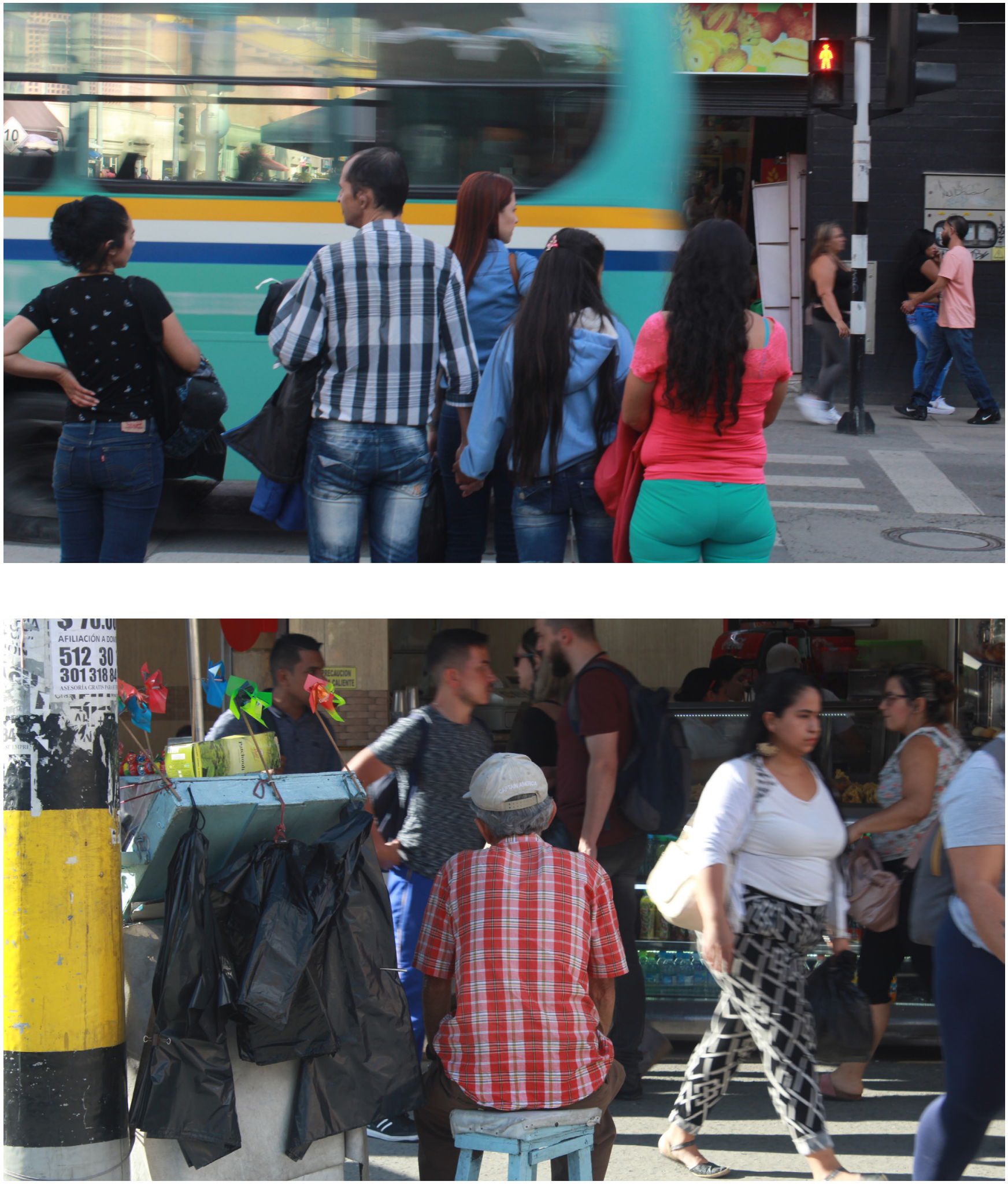

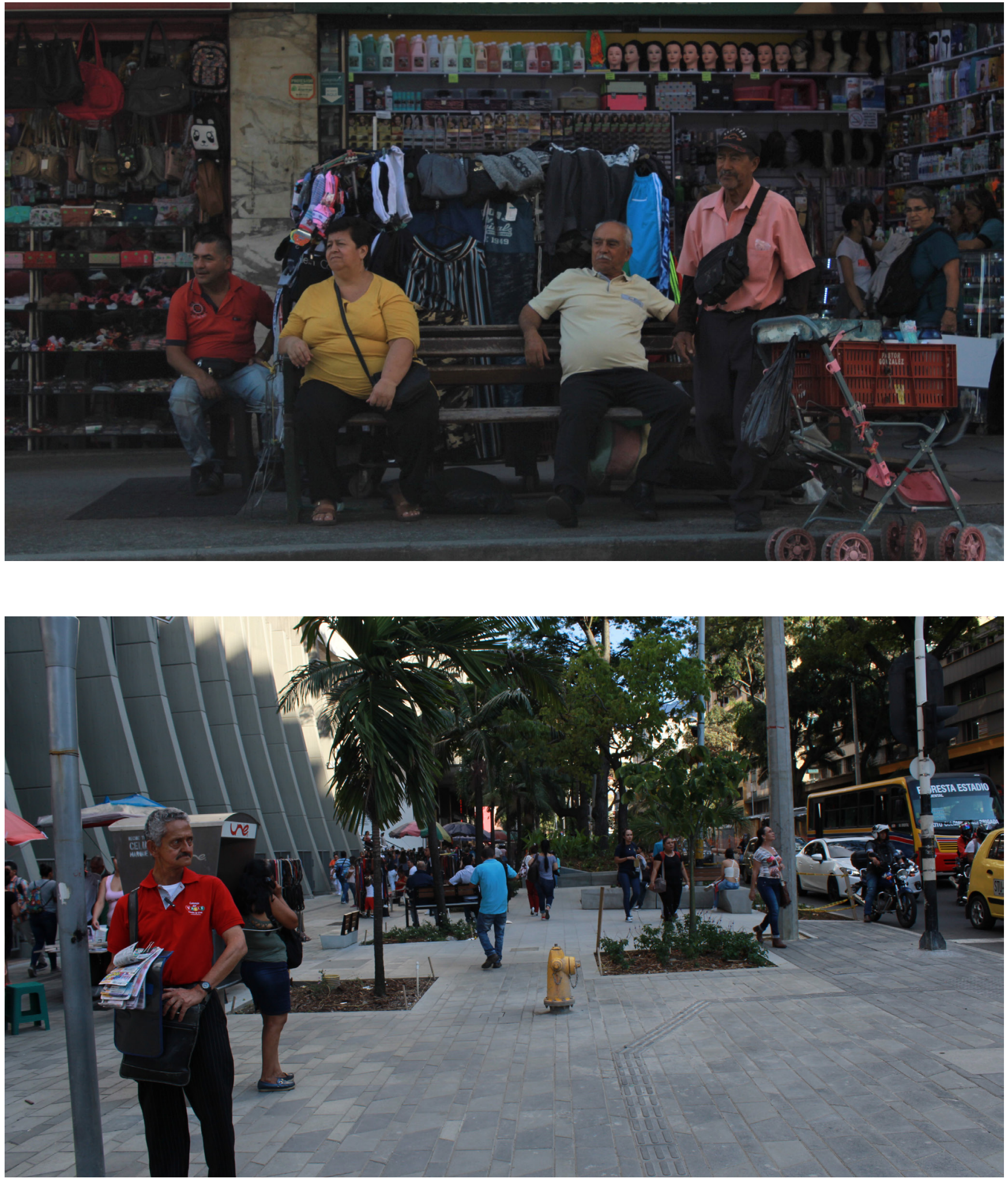

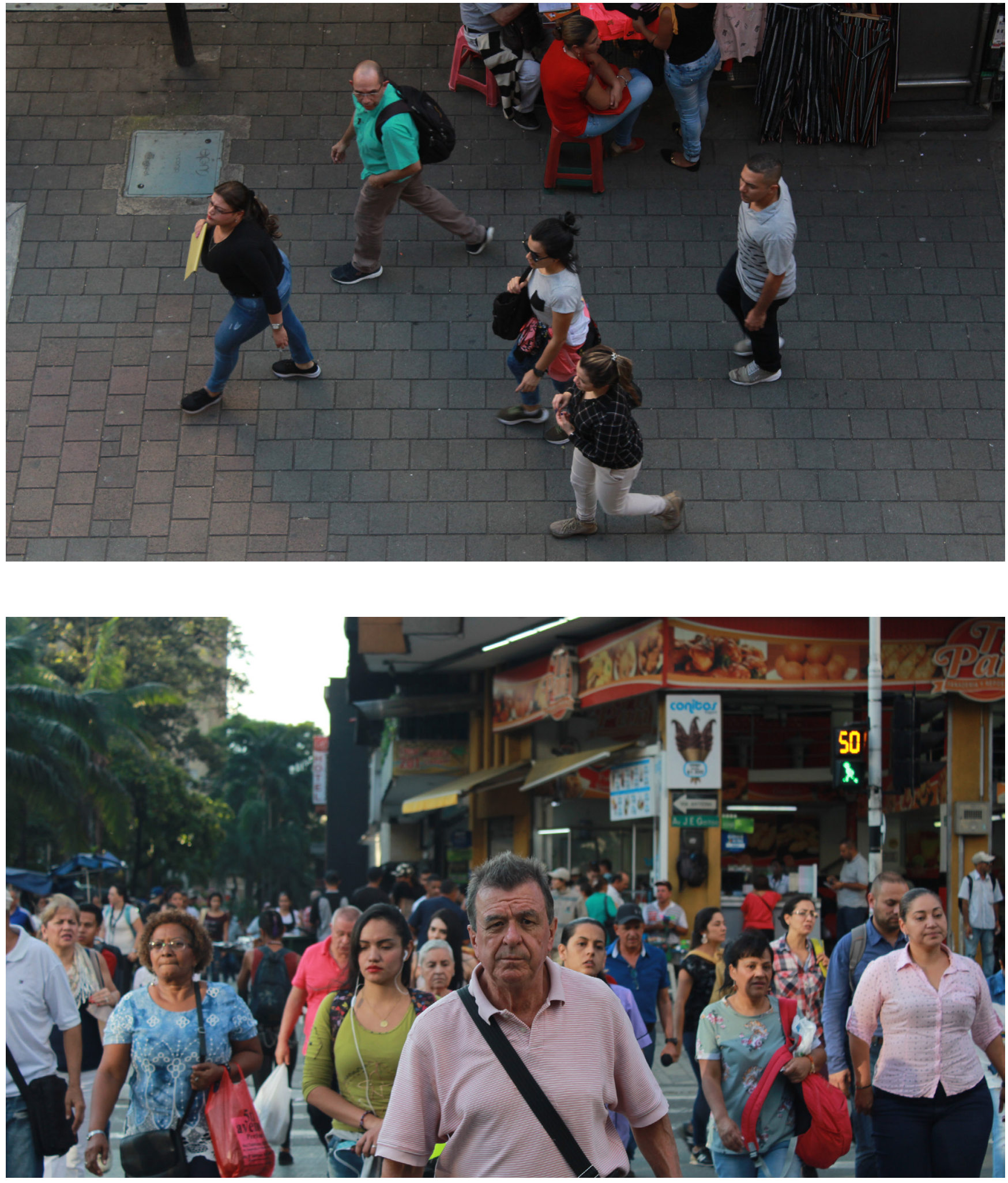

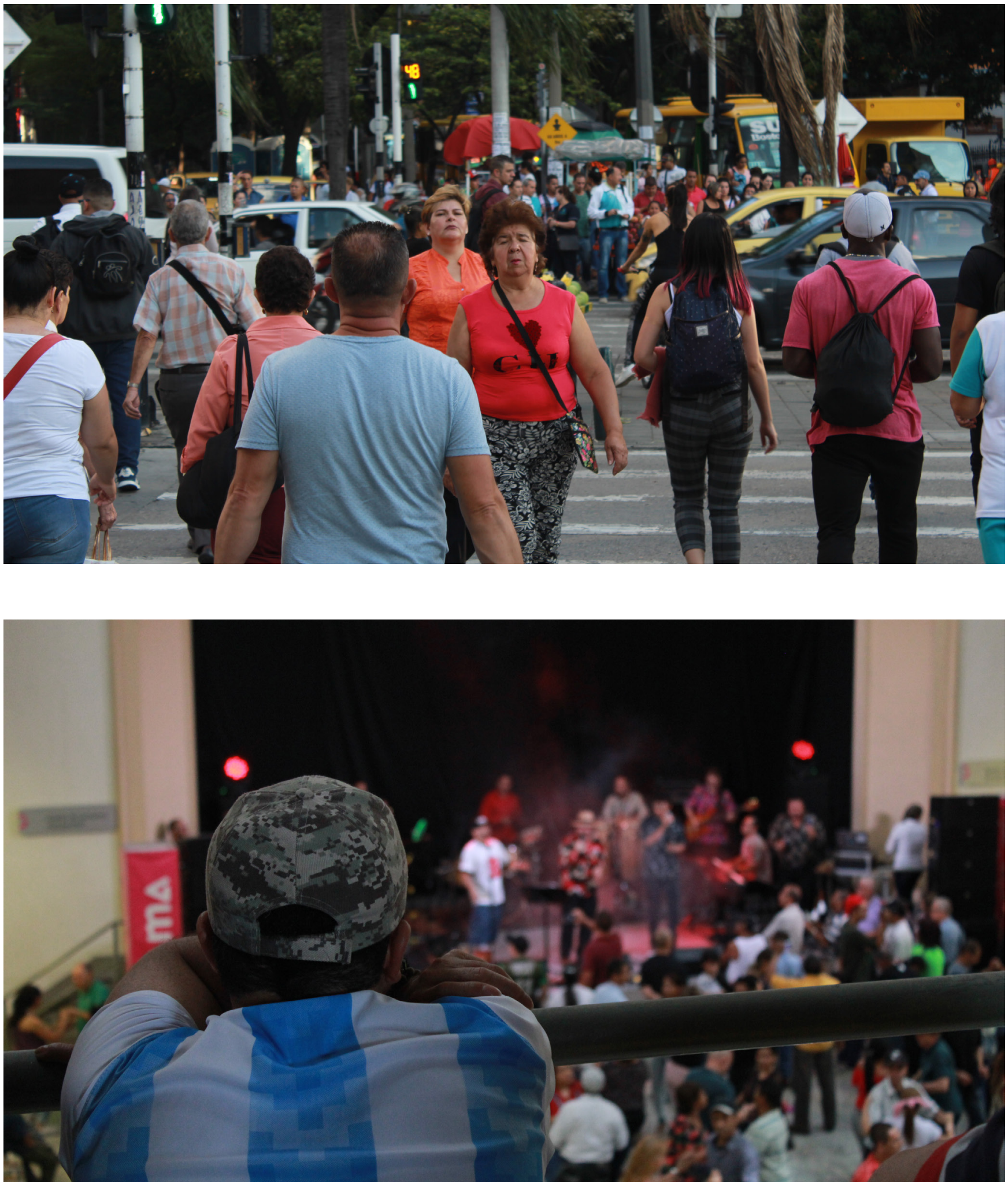
107

comunicación

número 40

Enero - junio

2019

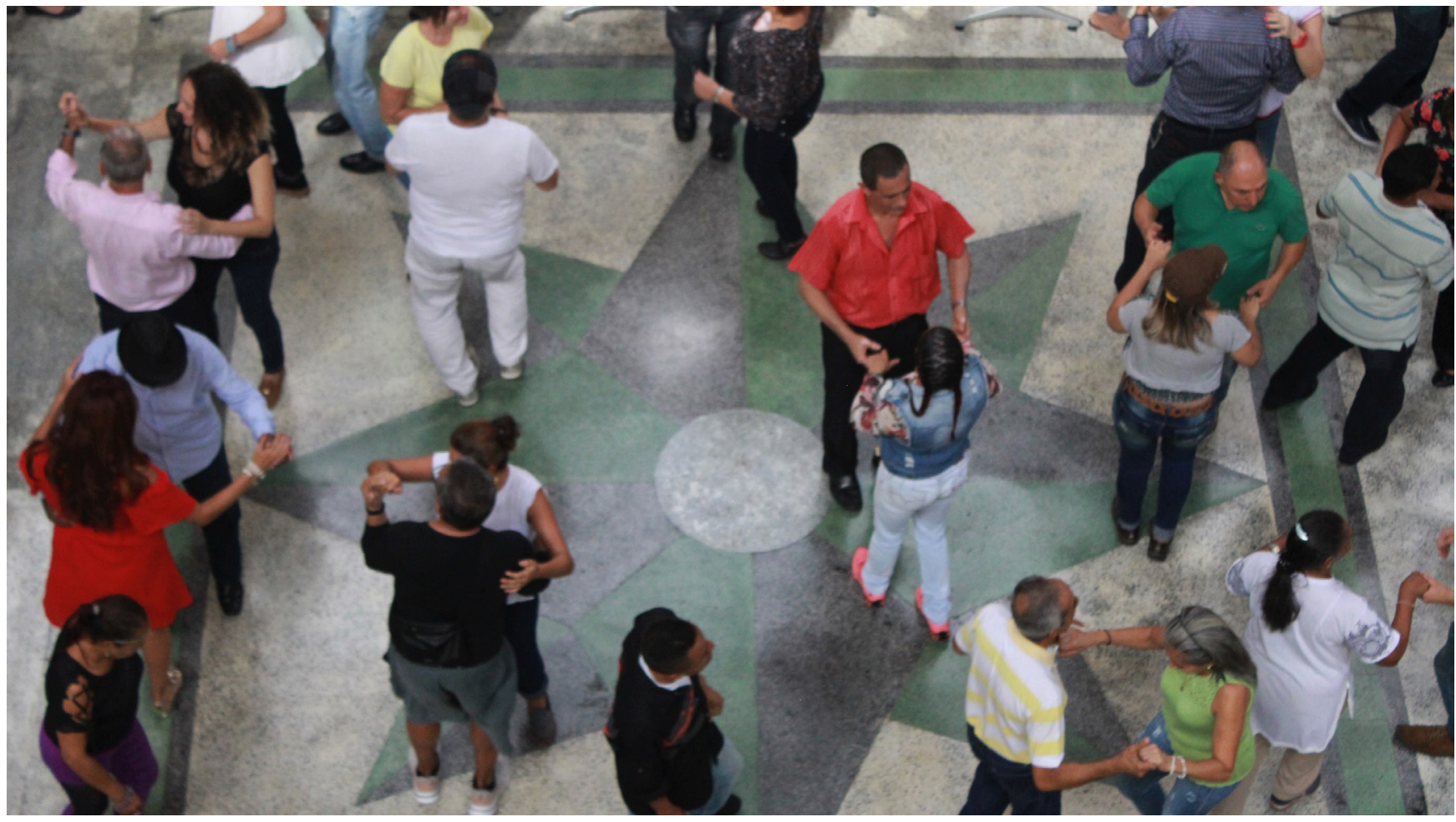

